20

\title{
Оптическое просветление биологических тканей рядом дисахаров
}

\author{
(C) К.В. Березин ${ }^{1}$, К.Н. Дворецкий ${ }^{2}$, В.В. Нечаев ${ }^{3}$, А.В. Новоселова ${ }^{1}$, А.М. Лихтер ${ }^{1}$, И.Т. Шагаутдинова ${ }^{1}$, \\ E.В. Грабарчук ${ }^{4}$, В.В. Тучин ${ }^{1,5,6}$ \\ ${ }^{1}$ Саратовский национальный исследовательский государственный университет им. Н.Г. Чернышевского, \\ 410012 Саратов, Россия \\ ${ }^{2}$ Саратовский государственный медицинский университет им. В.И. Разумовского, \\ 410012 Саратов, Россия \\ ${ }^{3}$ Саратовский государственный технический университет им. Ю.А. Гагарина, \\ 410054 Саратов, Россия \\ ${ }^{4}$ Астраханский государственный университет, \\ 414000 Астрахань, Россия \\ ${ }^{5}$ Институт проблем точной механики и управления РАН, \\ 410028 Саратов, Россия \\ ${ }^{6}$ Национальный исследовательский Томский государственный университет, \\ 634050 Томск, Россия \\ ฯ e-mail: dcn@yandex.ru
}

Поступила в редакцию 15.12.2020 г.

В окончательной редакции 12.02.2021 г.

Принята к публикации 26.02.2021 г.

Методами классической молекулярной динамики (GROMACS), молекулярного докинга (AutoDock Vina) и квантовой химии (PM6 и DFT/B3LYP) исследовано взаимодействие пяти иммерсионных агентов на основе растворов дисахаров (сахарозы, мальтозы, лактозы, трегалозы и целлобиозы) с миметическим пептидом коллагена $(\mathrm{GPH})_{3}$ как одним из основных компонентов биологических тканей. В результате комплексного молекулярного моделирования для этих агентов предсказаны такие параметры, как потенциал оптического просветления для кожи крысы и эффективность оптического просветления для кожи человека. Обсуждаются причины значительного различия в значениях параметров оптического просветления иммерсионных агентов, принадлежащих к одной молекулярной группе.

Ключевые слова: оптическое просветление биотканей, молекулярная динамика, молекулярный докинг, квантовая химия.

DOI: $10.21883 /$ OS.2021.06.50977.8k-21

\section{Введение}

Использование современных методов фотомедицины и биомедицинской оптики для диагностики и терапии заболеваний сопряжено с трудностями, которые возникают из-за того, что кожа и многие другие биоткани проявляют сильное упругое рассеяние света в видимой и ближней инфракрасной областях. Упругое рассеяние возникает за счет неоднородностей показателей преломления на границах различных макромолекулярных структур в основном на коллагеновых волокнах, которые преимущественно ответственны за рассеяние света в коже [1-3]. Эти трудности преодолеваются путем введения в ткань биосовместимых молекулярных агентов, которые в той или иной степени способствуют ее оптическому просветлению [2-6]. Экспериментальным in vitro, ex vivo и in vivo исследованиям просветления различных типов биотканей посвящено довольно много работ [1-10], что говорит об актуальности проблемы. В работах [4-8] описаны уникальные технологии оптического просветления для визуализации с высоким пространственным разрешением объемных биологических объектов. Однако эти технологии не применимы в исследованиях ex vivo и in vivo, поскольку используют фиксированную ткань, процедуры полной дегидратация и растворения липидов. Недавние исследования по развитию технологий оптического просветления для ex vivo и in vivo биологических тканей можно найти в работах [2-6,9-12]. Например, в работе [11] рассмотрено влияние модельного сахарного диабета на оптическое просветления кожи лабораторных мышей, а в работах $[10,12]$ путем визуализации с помощью двухфотонной автофлуоресценции и второй оптической гармоники (SHG-imaging) исследовался механизм оптического просветления кожи при использовании глицерина и рентгено-контрастного агента омнипака (йогексола) в качестве просветляющих агентов.

Тем не менее механизмы оптического просветления на молекулярном уровне до сих пор однозначно не определены. Молекулярному моделированию процессов, ответственных за оптическое просветление кожи, посвящен ряд работ: в $[1,13,14]$ с помощью классической молекулярной динамики, а в работах $[15,16]$ с помощью квантовой химии исследован процесс взаимодействия иммерсионных агентов с коллагеном как одним из основных компонентов биологических тканей. 
В работе [17] представлен обзор ex vivo и in vivo исследований, посвященных оптическому просветлению биотканей. В работе [18] представлены результаты исследований дегидратирующих свойств просветляющих агентов и отмечается, что дегидратация это только один из возможных механизмов, приводящих к просветлению биотканей. Проведение исследований в этой области открывает путь к пониманию молекулярных процессов, которые приводят к оптическому просветлению биотканей, что в свою очередь позволит находить эффективные просветляющие агенты с заданными свойствами.

В настоящей работе, с целью предсказания значений потенциала оптического просветления (ПП) для кожи крысы и эффективности оптического просветления (ЭП) кожи человека, было исследовано взаимодействие ряда просветляющих иммерсионных агентов, относящихся к группе дисахаридов (сахароза, мальтоза, лактоза, трегалоза и целлобиоза), с миметическими пептидом коллагена $(\mathrm{GPH})_{3}$ с использованием методов классической молекулярной динамики и квантовой химии.

\section{1. Методика молекулярного моделирования}

В качестве молекулярной модели коллагена был использован миметический пептид коллагена $(\mathrm{GPH})_{3}[19]$, составляющий основу большей части регулярных доменов коллагена человека. Такие относительно небольшие синтетические пептиды часто используются для молекулярного моделирования коллагенов. Трехмерная модель пептида строилась по данным из Protein Data Bank (PDB) с последующим добавлением атомов водорода и оптимизации структуры методом молекулярной динамики [20]. В качестве иммерсионных просветляющих агентов нами были рассмотрены пять молекул дисахаров, для двух из них (сахароза, мальтоза) в работах $[9,14]$ имеются экспериментальные данные по ПП. Молекулярное моделирование взаимодействия просветляющих агентов с коллагеном проводилось в несколько этапов.

Ha первом этапе методом DFT/B3LYP/6$311+\mathrm{G}(\mathrm{d}, \mathrm{p}) \quad[21,22]$ с использованием программы GAUSSIAN [23] были определены и рассчитаны все самые низкоэнергетические конформеры рассматриваемых просветляющих агентов в изолированном состоянии. Вычисленные молекулярные параметры в дальнейшем использовались при моделировании этих систем в рамках классической молекулярной динамики и молекулярного докинга. Также были вычислены волновые числа колебательных переходов, которые оказались положительными, что дополнительно свидетельствует о нахождении молекулярных систем в локальных минимумах.

На втором этапе моделирования методами классической молекулярной динамики анализировалось образование водородных связей между пептидом коллагена $\left((\mathrm{GPH})_{3}\right)_{9}$ и выбранными иммерсионными агента- ми. Молекулярное моделирование взаимодействия этих агентов с коллагеном проводилось с помощью пакета классической молекулярной динамики GROMACS [24] с силовым полем AMBER-03 [25]. Модельная сцена представляет собой трехмерную ячейку в форме прямоугольного параллелепипеда со следующими длинами сторон: $3 \times 3 \times 9 \mathrm{~nm}$. Границы ячейки выбирались периодическими (в случае столкновения с границей молекула проходит через нее, появляясь со стороны противоположной границы). Перед началом каждого моделирования 20 молекул агента распределяются случайным образом в пределах ячейки. Начальные скорости атомов задавались с помощью генератора случайных чисел пакета GROMACS и имели максвелловское распределение, соответствующее выбранной температуре. Для моделирования системы использовались термостат и баростат Берендсена [26], обеспечивающие сходимость температуры и давления системы к установленным значениям: $T_{0}=300 \mathrm{~K}$ и $P_{0}=1 \mathrm{bar}$. Временной шаг моделирования был выбран равным 0.0001 ps, а полное время моделирования составило 100 ps. Состояние системы записывалось каждые 0.1 ps. Записанные траектории движения молекул обрабатывались средствами пакета GROMACS и с помощью программы VMD (Visual Molecular Dynamics) [27]. Для каждой исследуемой системы моделирование повторялось 30 раз, полученные результаты усреднялись.

При анализе полученных в результате моделирования траекторий движения молекул считалось, что между атомами образуется водородная связь, если выполняются следующие геометрические критерии: $R \leq 3.5 \AA$ [28] и $\varphi \leq 30^{\circ}$, где $R$ - расстояние между атомом ,донора““ $\mathrm{A}$, ковалентно связанным с атомом водорода $\mathrm{H}$, и атомом „акцептора“ В другой молекулы (или функциональной группы той же молекулы), а $\varphi-$ угол, образованный связями АН и АВ. Пример такого взаимодействия приведен на рис. 1. В рамках этого этапа моделирования было оценено среднее число водородных связей, образовавшихся между низкомолекулярными агентами и коллагеном в единицу времени.

На третьем этапе моделирования для оценки энергии межмолекулярного взаимодействия выбранных просветляющих агентов с коллагеном был использован минимальный фрагмент миметического пептида, сохраняющий регулярную структуру - $\left((\mathrm{GPH})_{3}\right)_{2}$, состоящий из 231 атома (рис. 2, $a$ ), структура которого предварительно оптимизировалась в рамках полуэмпирического метода PM6 [29]. Как видно из рис. 2, $a$, посадочный молекулярный карман представляет собой участок пептида размером приблизительно 10 на $12 \AA$, в котором имеются четыре доступные для межмолекулярного связывания функциональные группы: две карбонильные (одна на остатке глицина - 2, другая на остатке гидроксипролина -3 одной и той же $\alpha$-цепи) и две спиртовые -1 и 4 на остатках гидроксипролинов различных $\alpha$-цепей.

Оптимизированная структура модели коллагена использовалась для проведения молекулярного докин- 


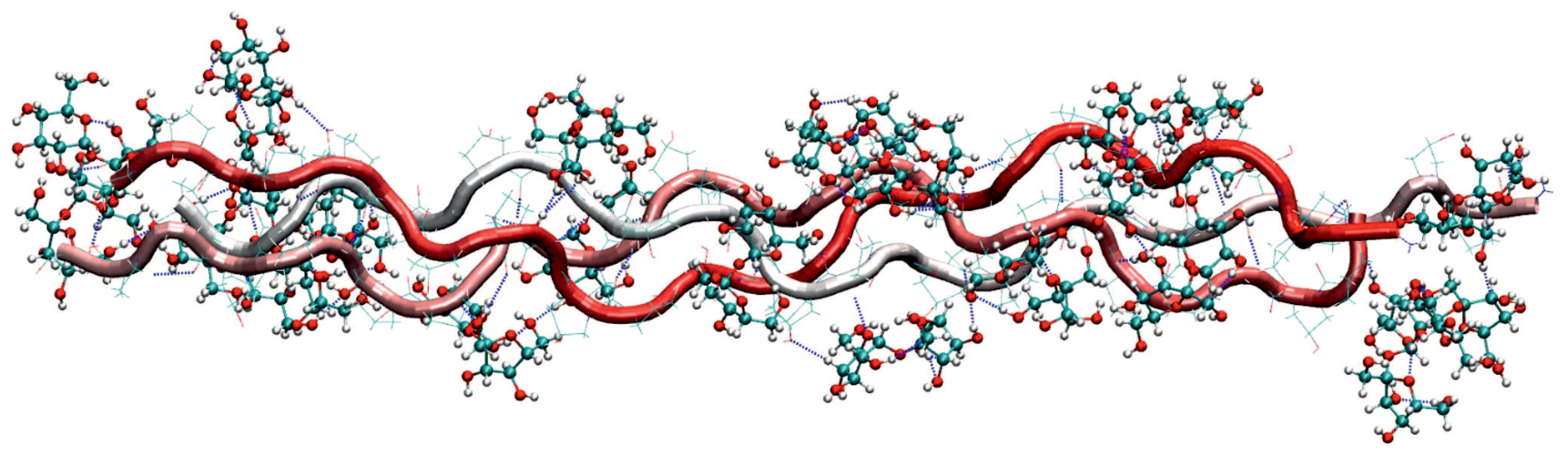

Рис. 1. Пространственная структура водородосвязанного комплекса молекул сахарозы и коллагенового пептида $\left((\mathrm{GPH})_{3}\right)_{9}$, полученная в рамках классической молекулярной динамики.
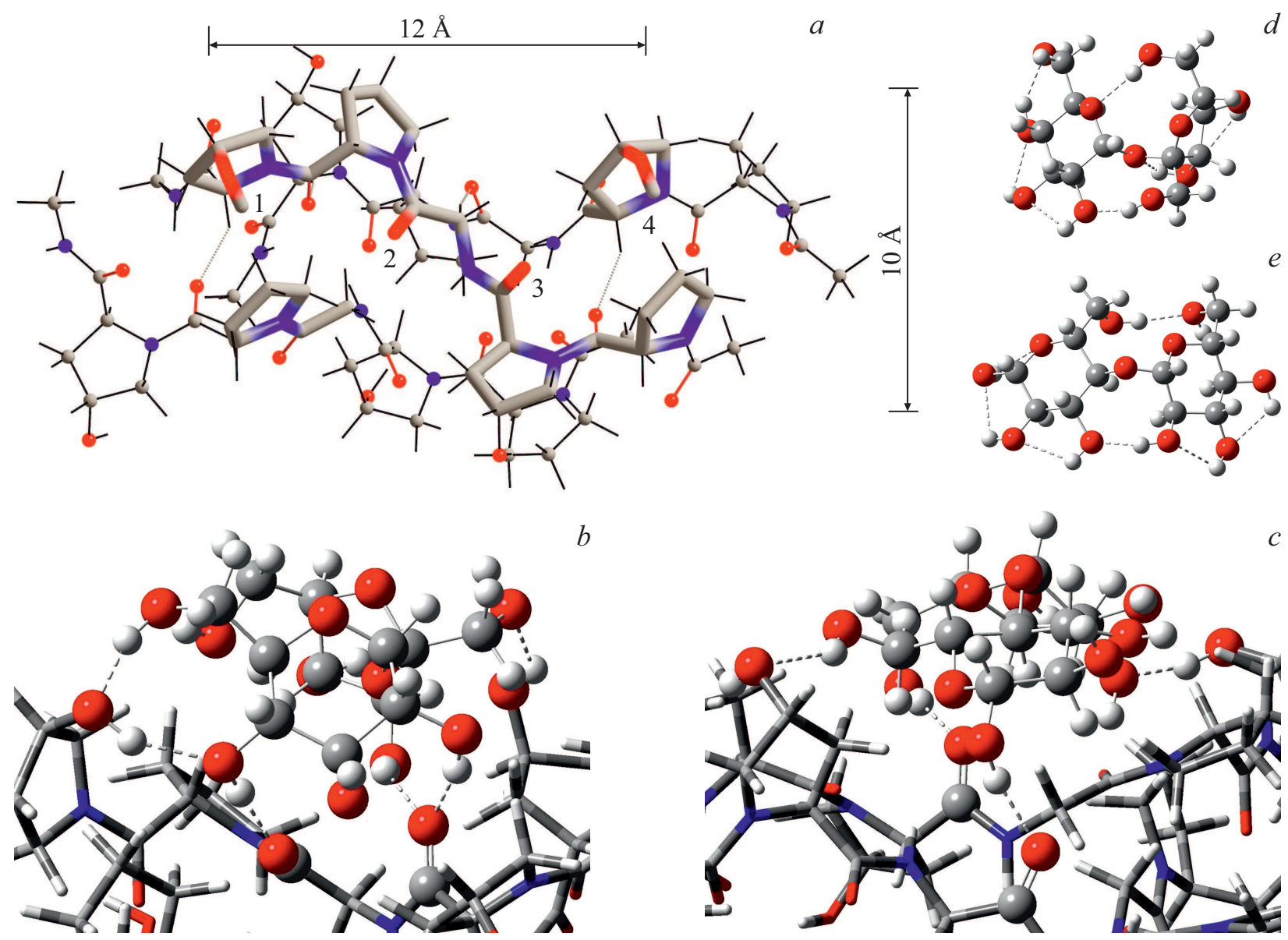

Рис. 2. $a-$ - ррагмент миметического пептида $\left((\mathrm{GPH})_{3}\right)_{2}$, оптимизированного полуэмпирическим методом РМ6 (цифрами обозначены молекулярные группы, участвующие в образовании водородных связей с просветляющими агентами); $b, c-$ водородосвязанные комплексы, образованные фрагментом коллагена $\left((\mathrm{GPH})_{3}\right)_{2}$ и приведенными далее на рисунке иммерсионными просветляющими агентами; $d, e$ - пространственные конфигурации самых низкоэнергетических конформеров некоторых просветляющих агентов (сахарозы и мальтоза), вычисленные методом B3LYP/6-311+(d,p). Штриховыми линиями на рисунке показаны водородные связи.

га с просветляющими агентами в рамках программы AutoDockVina [30]. После проведения молекулярного докинга для каждой взаимодействующей системы выбирались первые десять наиболее выгодных конфигураций, которые далее оптимизировались полуэмпирическим методом РM6. Затем путем проведения однократной SCFпроцедуры методом DFT/B3LYP/6-31G(d) вычислялись полные электронные энергии комплексов. Аналогичная 
процедура была использована для получения значений полной электронной энергии просветляющих агентов и пептидного фрагмента. Энергия межмолекулярного взаимодействия рассчитывалась, как разность полных энергий комплекса и суммы энергий отдельных его составляющих. В итоге выбирались максимальные значения энергий межмолекулярного взаимодействия, которые соответствуют наиболее вероятным структурам комплексов. На рис. $2, c, b$ (на примере сахарозы и мальтозы) показаны структуры водородосвязанных комплексов, образованных фрагментами коллагена $\left((\mathrm{GPH})_{3}\right)_{2}$ и молекулами иммерсионных агентов.

\section{2. Результаты и обсуждение}

Примеры рассчитанных в рамках метода DFT/B3LYP/6-311+G(d,p) пространственных конфигураций низкоэнергетических изолированных конформеров иммерсионных агентов показаны на рис. $2, d, e$. Из рисунка видно, что для дисахаров наиболее выгодными в изолированном состоянии являются конформации, в которых образуется максимальное число внутримолекулярных водородных связей.

Для удобства обсуждения количественных экспериментальных и теоретических параметров все они приведены в таблице. В таблице под ПП [1] понимается наклон линии регрессии отношения приведенного коэффициента рассеяния до и после 45 min действия иммерсионного агента в зависимости от его концентрации, выраженной в молях. Следует заметить, что значения ПП в работах [19] и [20] получены при разных диапазонах концентрации иммерсионного агента. Для оценки ЭП кожи человека in vivo в работе [16] определялись значения коэффициента рассеяния света, полученные с помощью усреднённого ОКТ А-скана на участке дермы глубиной от 350 до $700 \mu \mathrm{m}$. В качестве численного выражения ЭП кожи были использованы значения модуля средней скорости изменения коэффициента рассеяния (на временном отрезке от 5 до $35 \mathrm{~min}$ ) при воздействии водного раствора иммерсионного агента средней концентрации $(60 \%)$.

Из таблицы видно, что не наблюдается прямой корреляции между числом образованных межмолекулярных водородных связей и энергией межмолекулярного взаимодействия. Это связано с тем, что на энергию межмолекулярного взаимодействия значительно влияют еще два фактора. Первый фактор связан с энергией, которая тратится на структурную подстройку молекулярных систем при создании межмолекулярного комплекса. Второй фактор связан с конкуренцией между внутримолекулярными водородными связями и межмолекулярными. То есть, если системе энергетически выгодно не разрывать внутримолекулярную водородную связь, то межмолекулярная связь не образуется. Именно влиянием этих двух факторов объясняется в [15] различие в энергии
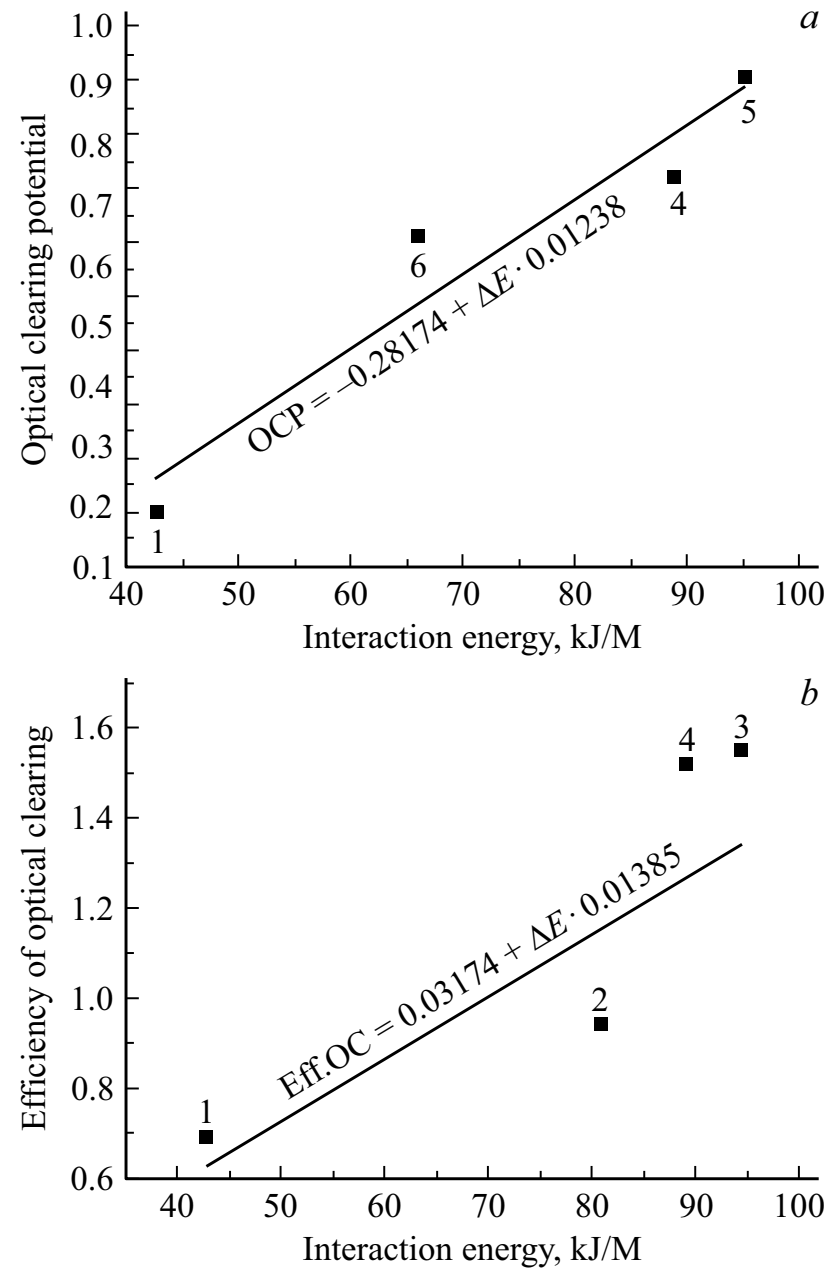

Рис. 3. Зависимость ПП кожи крысы (a) [14], ЭП кожи человека $(b)$ [16] от энергии взаимодействия (по модулю) пептида коллагена с молекулами просветляющих агентов: 1 глицерола, 2 - рибозы, 3 - глюкозы, 4 - фруктозы, 5 сахарозы и 6 - мальтозы. Сплошными линиями обозначены линейные аппроксимации этих зависимостей. Также на графиках приведены уравнения регрессии.

межмолекулярных взаимодействий и соответственно в ПП в сходных молекулярных структурах.

Сравним приведенные в таблице экспериментальные данные по ПП для фруктозы, сахарозы и мальтозы с результатами молекулярного моделирования. Надо отметить, что величина ПП у фруктозы в работе [13] на $15 \%$ больше, чем у сахарозы, а в работе [14], наоборот, на $18 \%$ меньше. Данные, полученные с помощью классической молекулярной динамики, предсказывают увеличение на $18 \%$ среднего числа водородных связей в единицу времени, что должно приводить к увеличению ПП [13]. Данные по энергии межмолекулярного взаимодействия, полученные с помощью методов квантовой химии, также показывают увеличение энергии на $6 \%$, что тоже предсказывает увеличение ПП при переходе от фруктозы к сахарозе. 
Длина межмолекулярных водородных связей $l$ и скорость их образования $N$, энергия межмолекулярных взаимодействий $\Delta E$ между фрагментом коллагена $(\mathrm{GPH})_{3}$ и иммерсионными агентами, рассчитанные методом PM6/B3LYP/6-31G(d), экспериментальные (ех vivo, in vivo) и теоретические значения ПП для кожи крысы, а также экспериментальные (in vivo) и теоретические значения ЭП для кожи человека

\begin{tabular}{|c|c|c|c|c|c|c|}
\hline \multicolumn{2}{|c|}{ Агент } & \multirow{2}{*}{$\begin{array}{c}l, \AA \\
1.74,1.91,1.92 \\
1.93,2.44\end{array}$} & \multirow{2}{*}{$\begin{array}{c}N, \mathrm{ps}^{-1} \\
0.840[15]\end{array}$} & \multirow{2}{*}{$\begin{array}{l}\Delta E, \mathrm{~kJ} / \mathrm{M} \\
-42.8[16]\end{array}$} & \multirow{2}{*}{$\frac{\text { ПП }}{0.192[1]}$} & \multirow{2}{*}{$\frac{Э П}{0.69[16]}$} \\
\hline Спирт & Глицерол & & & & & \\
\hline \multirow[t]{3}{*}{ Моносахара } & Рибоза & $\begin{array}{l}1.84,1.90 \\
1.91,1.95 \\
\end{array}$ & 0.918 & $-80.9[16]$ & - & $0.94[16]$ \\
\hline & Глюкоза & $\begin{array}{l}1.68,1.71, \\
1.84,1.94\end{array}$ & 0.943 & $-94.5[16]$ & $0.384[1]$ & $1.55[16]$ \\
\hline & Фруктоза & $\begin{array}{c}1.82,1.84,1.90 \\
1.96,2.23 \\
\end{array}$ & 0.669 & $-89.2[16]$ & $\begin{array}{l}0.75[20] \\
0.447[1] \\
\end{array}$ & $1.52[16]$ \\
\hline \multirow[t]{5}{*}{ Дисахара } & Сахароза & $\begin{array}{l}1.70,1.71,1.78 \\
1.82,1.90,1.91 \\
\end{array}$ & 0.812 & -95.2 & $\begin{array}{l}0.91[20] \\
0.379[1] \\
\end{array}$ & $1.35^{* *}$ \\
\hline & Мальтоза & $\begin{array}{l}1.89,1.90 \\
2.59,1.94\end{array}$ & 0.949 & -66.0 & $0.65[20]$ & $0.95^{* *}$ \\
\hline & Лактоза & $\begin{array}{l}1.76,1.78 \\
1.86,2.27 \\
\end{array}$ & 0.883 & -61.0 & $0.47^{*}$ & $0.88^{* *}$ \\
\hline & Трегалоза & $\begin{array}{c}1.80,1.82,1.89 \\
1.91,2.04 \\
\end{array}$ & 0.952 & -86.3 & $0.79^{*}$ & $1.23^{* *}$ \\
\hline & Целлобиоза & $\begin{array}{l}1.72,1.76 \\
1.99,2.40\end{array}$ & 0.971 & -135.8 & $1.40^{*}$ & $1.91^{* *}$ \\
\hline
\end{tabular}

Примечание. * Теоретически предсказанные значения ПП кожи крысы ex vivo на основе регрессионного анализа имеющихся в работе [14] экспериментальных данных. ** Теоретически предсказанные значения эффективности оптического просветления кожи человека in vivo на основе регрессионного анализа имеющихся в работе [16] экспериментальных данных.

Теперь сравним экспериментальные значения ПП у сахарозы и мальтозы. Как видно из таблицы, ПП у мальтозы на $29 \%$ ниже, чем у сахарозы. Молекулярная динамика предсказывает обратную ситуацию, поскольку среднее число водородных связей в единицу времени не убывает по сравнению с сахарозой, а, наоборот, возрастает на $14 \%$. При рассмотрении результатов, полученных с помощью методов квантовой химии, мы наблюдаем ситуацию, которая качественно согласуется с экспериментом, так как энергия межмолекулярного взаимодействия уменьшается на $31 \%$ при переходе от сахарозы к мальтозе. В данном случае методы молекулярной динамики и квантовой химии дали противоположные результаты. На наш взгляд, это связано с тем, что в методах квантовой химии более корректно учитывается конкуренция между внутримолекулярными и межмолекулярными водородными связями.

Используя экспериментальные данные из работ $[13,14,16]$, мы построили линейные аппроксимации зависимостей экспериментальных значений ПП и ЭП от энергии межмолекулярного взаимодействия пептида коллагена с иммерсионными агентами (рис. 3). Так как имеющихся в литературе экспериментальных данных по оптическому просветлению рассматриваемых в данной работе имммерсионных агентов явно недостаточно для получения надежной аппроксимации, рис. 3 содержит наряду с данными по дисахарам и имеющиеся в нашем распоряжении данные по моносахарам. Также на рис. 3 представлен трехатомный спирт глицерол. Этот спирт очень часто используется в качестве иммерсионного агента и поэтому его данные по оптическому просветлению кожи были выбраны нами в качестве референсного (опорного) значения. В результате полученных аппроксимаций были вычислены теоретические значения ПП для кожи крысы и ЭП для кожи человека, которые представлены в таблице. Как видно из таблицы, наибольшие значения ПП и ЭП предсказываются для молекулы целлобиозы. Увеличение по сравнению с сахарозой ПП для кожи крысы предсказывается на $54 \%$, а ЭП для кожи человека - на $42 \%$ (теоретические значения ЭП молекулы сахарозы сравниваются с теоретическими значениями для молекулы целлобиозы). Метод молекулярной динамики также предсказывает наибольшие значения ПП и ЭП для молекулы целлобиозы вследствие максимального значения среднего числа водородных связей в единицу времени, которое на $20 \%$ отличается от аналогичного значения для молекулы сахарозы.

Вычисленные коэффициенты линейной корреляции между экспериментальными значениями ПП для кожи крысы и ЭП для кожи человека с вычисленной энергией межмолекулярного взаимодействия составили 
соответственно 0.96 и 0.84 . Несмотря на ограниченность имеющихся в нашем распоряжении экспериментальных данных, полученные значения статистической достоверности корреляционной связи (соответственно 0.95 и 0.90$)$ позволяют использовать линейную аппроксимацию в качестве выбранной теоретической модели. Также такие высокие значения коэффициентов корреляции позволяют говорить о принципиальной важности последиффузионного этапа оптического просветления [15], в котором происходит взаимодействие коллагена с просветляющими агентами и определяется влияние на оптическое просветление биотканей. Результаты исследования $[15,17]$ позволяют говорить о том, что в процессе такого взаимодействия происходит частичное замещение связанной с коллагеном воды. Это приводит к нарушению связующей сетки водородных связей и, как следствие, к обратимому процессу увеличения объема коллагеновых фибрилл, что в свою очередь уменьшает их показатель преломления и выравнивает его с межколлагеновой средой. Чем выше сродство просветляющего агента к коллагену, тем эффективнее идет этот процесс.

Bce вышеизложенное позволяет предположить, что следующим шагом для увеличения эффективности взаимодействия может быть подбор иммерсионного агента с такими структурными характеристиками, которые позволяли бы ему одновременно взаимодействовать сразу с несколькими молекулярными карманами коллагена. Примером такого эффективного просветляющего агента может служить молекулярная система полимерного типа, состоящая, например, из шестичленных моносахаридов, соединенных подвижной углеродно-кислородной цепочкой такой длины, чтобы насыщенные кольца сахара попадали в области молекулярных карманов коллагена и взаимодействовали с ними посредством своих гидроксильных групп. Но здесь необходимо также учитывать, что значительное увеличение размера молекул, используемых в качестве просветляющих агентов, приведет к увеличению вязкости вещества и, как следствие, к уменьшению скорости диффузии в биоткани, а также к увеличению времени его вымывания из биотканей.

\section{Выводы}

В результате комплексного молекулярного моделирования взаимодействия ряда дисахаридов с миметическим пептидом коллагена $(\mathrm{GPH})_{3}$ вычислены среднее число образованных водородных связей в единицу времени и энергии межмолекулярного взаимодействия. Используя зависимость между энергией межмолекулярного взаимодействия и такими характеристиками, как ПП для кожи крысы и ЭП для кожи человека, были предсказаны их численные значения. Наибольшие значения ПП и ЭП в ряду рассмотренных дисахаров предсказаны для молекулы целлобиозы. Полученные высокие значения корреляции между экспериментальными значениями па- раметров оптического просветления с энергией межмолекулярного взаимодействия говорят о важной роли последиффузионной стадии в процессе оптического просветления биотканей. Даны рекомендации по способу подбора наиболее эффективных просветляющих агентов.

\section{Финансирование работы}

Работа В.В. Тучина была поддержана грантом правительства Российской Федерации 075-15-2019-1885.

\section{Конфликт интересов}

Авторы заявляют, что у них нет конфликта интересов.

\section{Список литературы}

[1] Hirshburg J.M., Ravikumar K.M., Hwang W., Yeh A. // J. Biomed. Opt. 2010. V. 15. N 5. P. 055002. doi $10.1117 / 1.3484748$

[2] Тучин В.В. Оптика биологических тканей. Методы рассеяния света в медицинской диагностике, 2-е издание. М: Физматлит, 2012. 811 c.; Tuchin V.V. Tissue Optics: Light Scattering Methods and Instruments for Medical Diagnosis (SPIE Press Monograph. V. PM166) Second Edition. SPIE Publications, 2007. 882 p.

[3] Tuchin V.V. Optical Clearing of Tissues and Blood (SPIE Press Monograph. V. PM154). SPIE Publications, 2005. $256 \mathrm{p}$.

[4] Zhu D., Larin K.V., Luo Q., Tuchin V.V. // Laser Photonics Rev. 2013. V. 7. N 5. P. 732. doi 10.1002/lpor.201200056

[5] Genina E.A., Bashkatov A.N., Sinichkin Yu.P., Yanina I.Yu., Tuchin V.V. // J. Biomed. Photonics \& Eng. 2015. V. 1. N 1. P. 22. doi 10.18287/jbpe-2015-1-1-22

[6] Oliveira L.M.C., Tuchin V.V. The Optical Clearing Method: A New Tool for Clinical Practice and Biomedical Engineering. Basel: Springer Nature Switzerland AG, 2019. 177 p.

[7] Matryba P., Kaczmarek L., Golab J. // Laser \& Photon. Rev. 2019. V. 13. N 8. P. 1800292. doi 10.1002/lpor.201800292

[8] Ueda H.R., Erturk A., Chung K., Gradinaru V., Chedotal A., Tomancak P., Keller P.J. // Nat. Rev. Neurosci. 2020. V. 21. N 2. P. 61. doi 10.1038/s41583-019-0250-1

[9] Hirshburg J., Choi B., Nelson J.S., Yeh A.T. // Las. Surg. Medicine. 2007. V. 39. N 2. P. 140. doi 10.1002/lsm.20417

[10] Sdobnov A.Y., Darvin M.E., Genina E.A., Bashkatov A.N., Lademann J., Tuchin V.V. // Spectrochim. Acta A. 2018. V. 197. P. 216. doi 10.1016/j.saa.2018.01.085

[11] Tuchina D.K., Shi R., Bashkatov A.N., Genina E.A., Zhu D., Luo Q., Tuchin V.V. // J. Biophotonics. 2015. V. 8. N 4. P. 332. doi $10.1002 /$ jbio. 201400138

[12] Wen X., Mao Z., Han Z., Tuchin V.V., Zhu D. // J. Biophotonics. 2010. V. 3. N 1-2. P. 44. doi 10.1002/jbio. 200910080

[13] Hirshburg J.M. Chemical agent induced reduction of skin light scattering: doctoral dissertation. Texas A\&M University, 2009. P. 119.

[14] Feng $W$., Shi R., Ma N., Tuchina D.K., Tuchin V.V., Zhu D. // J. Biomed. Opt. 2016. V. 21. N 8. P. 081207. doi 10.1117/1.JBO.21.8.081207 
[15] Berezin K.V., Dvoretski K.N., Chernavina M.L., Likhter A.M., Smirnov V.V., Shagautdinova I.T., Antonova E.M., Stepanovich E.Yu., Dzhalmuhambetova E.A., Tuchin V.V. // J. Mol. Modeling. 2018. V. 24. N 2. P. 45. doi 10.1007/s00894-0183584-0

[16] Березин К.В., Дворецкий К.Н., Чернавина М.Л., Нечаев В.В., Лихтер А.М., Шагаутдинова И.Т., Антонова Е.М., Тучин В.В. // Опт. и спектр. 2019. Т. 127. В. 8. C. 329. doi 10.21883/OS.2019.08.48051.29-19; Berezin K.V., Dvoretski K.N., Chernavina M.L., Nechaev V.V., Likhter A.M., Shagautdinova I.T., Antonova E.M., Tuchin V.V. // Opt. Spectrosc. 2019. V. 127. N 8. P. 352. doi 10.1134/S0030400X19080071

[17] Bashkatov A.N., Berezin K.V., Dvoretskiy K.N., Chernavina M.L., Genina E.A., Genin V.D., Kochubey V.I., Lazareva E.N., Pravdin A.B., Shvachkina M.E., Timoshina P.A., Tuchina D.K., Yakovlev D.D., Yakovlev D.A., Yanina I.Yu., Zhernovaya O.S., Tuchin V.V. // J. Biomed. Opt. 2018. V. 23. N 9. P. 091416. doi 10.1117/1.JBO.23.9.091416

[18] Yu T., Wen X., Tuchin V.V., Luo Q., Zhu D. // J. Biomed. Opt. 2011. V. 16. N 9. P. 095002. doi 10.1117/1.3621515

[19] Okuyama K., Miyama K., Mizuno K., Bachinger H.P. // Biopolymers. 2012. V. 97. N 8. P. 607. doi 10.1002/bip.22048

[20] Cornell W.D., Cieplak P., Bayly C.I., Gould I.R., Merz K.M.Jr., Ferguson D.M., Spellmeyer D.C., Fox T., Caldwell J.W., Kollman P.A. // J. Am. Chem. Soc. 1995. V. 117. N 19. P. 5179. doi $10.1021 / \mathrm{ja00124a002}$

[21] Becke A.D. // J. Chem. Phys. 1993. V. 98. N 7. P. 5648. doi 10.1063/1.464913

[22] Lee C., Yang W., Parr R.G. // Phys. Rev. B. 1988. V. 37. N 2. P. 785. doi 10.1103/PhysRevB.37.785

[23] Frisch M.J., Trucks G.W., Schlegel H.B. et al. Gaussian09, Revision A.02. Pittsburgh PA: Gaussian, Inc. 2009.

[24] van der Spoel D., Lindahl E., Hess B., Groenhof G., Mark E.A., Berendsen H.J.C. // J. Comput. Chem. 2005. V. 26. N 16. P. 1701. doi 10.1002/jcc.20291

[25] Duan Y., Wu C., Chowdhury S., Lee M.C., Xiong G., Zhang W., Yang R., Cieplak P., Luo R., Lee T., Caldwell J., Wang J., Kollman P. // J. Comp. Chem. 2003. V. 24. N 16. P. 1999. doi 10.1002/jcc.10349

[26] Berendsen H.J.C., Postma J.P.M., van Gunsteren W.F., DiNola A., Haak J.R. // J. Chem. Phys. 1984. V. 81. N 8. P. 3884. doi 10.1063/1.448118

[27] Humphrey W., Dalke A., Schulten K. // J. Mol. Graph. 1996. V. 14. N 1. P. 33. doi 10.1016/0263-7855(96)00018-5

[28] Loof H.D., Nilsson L., Rigler R. // J. Am. Chem. Soc. 1992. V. 114. N 11. P. 4028. doi 0.1021/ja00037a002

[29] Stewart J.J.P. // J. Mol. Model. 2007. V. 13. N 12. P. 1173. doi 10.1007/s00894-007-0233-4

[30] Trott O., Olson A.J. // J. Comp. Chem. 2010. V. 31. N 2. P. 455. doi $10.1002 /$ jcc. 21334 